\title{
Tetraplegics and the justice of resource allocation ${ }^{1}$
}

\author{
P Walsh $\mathrm{PhD}$ \\ Lecturer in Medical Ethics, Centre of Medical Law and Ethics, Kings College London, \\ Strand, London WC2R 2LS, England.
}
Keywords: tetraplegia; resource allocation; quality adjusted life years; ethical aspects.

With recent advances in medical technology, increasing numbers of people survive injury, disease and congenital disorder by becoming permanently dependent on lifesupporting equipment. One of the most dramatic examples of permanent technology dependence is that caused by high spinal cord injury. The treatment of the victims of such injury, who suffer almost total motor and sensory failure and respiratory insufficiency, raises difficult ethical questions. One of the most pressing of these is the question of the reliability of quality-of-life judgements and of our methods of assessing healthcare priorities. Since our decisions as to the level of care possible in a situation of scarce resources affects the quality of life of patients, and, for some, the quantity also, they must be informed not only by considerations of efficiency but by an efficiency tempered by justice. Rationality demands as much.

The ethical issues surrounding the treatment of high lesion tetraplegia are hard ones: should mentally competent individuals with a non terminal but terrible condition, for example, be allowed to die, if they so wish? Since death would have to be assisted, of what relevance is the much vaunted notion of autonomy to a fully rational individual whose only exercise of self determination may be a decision to die, with which no one can comply? Do moral considerations set any limits on the invasiveness of a treatment and therefore its acceptability? But this sort of catastrophic injury also forces us to think hard about the point of postponing death in cases where post-

\footnotetext{
${ }^{1}$ Paper read at the First European Conference on Domiciliary Ventilation and High Spinal Cord Lesion in Southport, England, in October 1991.
}

ponement is possible. The wisdom of unnaturally extending a life in circumstances like these seems to depend on quantifying the benefits and burdens of treatment and assessing the resultant quality of life of the patient. It also depends, in a situation of scarce medical resources, on whether society can afford the level of care and financial support necessary when that need is unlikely to diminish with time. It was to reconcile these two aspects of medical decision making that Quality Adjusted Life Years (QALYs) were developed, most notably by the economist Alan Williams of York University. The concept has subsequently been taken up more or less enthusiastically by health managers, with 28 out of 76 district health authorities considering using QALYs, 37 not and 11 still undecided. ${ }^{1}$ The QALY method entails multiplying each year of life of a patient who survives a life threatening condition by a fraction which expresses the impairment of quality of life as experienced by that patient. From that calculation and from the cost of a treatment or procedure, it is claimed, a cost per QALY can be derived as a measure of 'value for money'. The hidden, but overtly utilitarian, assumption of this method is, of course, that such calculations assure that maximum benefit (understood as the greatest benefit overall) is attained. Consequently, a high priority healthcare activity will be one where the cost per QALY is low and a low priority activity will be one where the cost per QALY is high.

Clearly, when quality of life and the cost of long term care are important considerations in treatment decisions, the choice of measure and the interpretation of its results are critical. And if, as with the QALY method, this process results in the denial of 
some services to some patients, we need to be very clear about the implications of such a practice and the values underpinning it. Its moral acceptability may depend in part on who the losers turn out to be and why. Since ventilator dependent tetraplegics do badly on the QALY matrix - and are, therefore, likely to be some of the losers - they bring sharply into focus the moral issues surrounding the reliability of quality of life judgements or measures and the justice of the QALY method of assessing health priorities. It is with this second sort of moral question that I shall be concerned.

Perhaps all understanding of a life different from our own and of its value to the person whose life it is, is largely an imaginative exercise dependent upon the imaginer's own experience and ability to empathise. Hence the well known difficulties of making quality of life judgements. But what on earth is it like to be a tetraplegic? When one tries to imagine what it is like not to be able to move, or feel anything from the neck down and to be permanently plugged into a ventilator one almost draws a blank. What does it mean, for instance, to lose one's sense of space? Does that mean that the world presents itself as if on a huge cinema screen? What is it like to act when, again using available technology, all action is action at a distance? How does it feel to hand over one's physical integrity to another forever - to be washed, clothed, fed and have all one's bodily functions seen to by a parent, for example? Some insight is provided by tetraplegic patients themselves, of course. One ordinarily vain young woman may speak of the frustration of not being able to arrange her hair and make-up the way she wants it and of the lack of privacy that accompanies 24-hour nursing; another patient of asking his nurse if he could come and watch when she needed to use the bathroom, just in order to draw her attention to the fact that she expected him to 'perform' in public every day! But no matter how vivid these little vignettes, they are like matches being struck in a dark room: one catches a brief glimpse of some dimly lit corner but never a picture of the whole.

Of course life is not all dark for tetraplegics: using very advanced technology, specialised programmes have been developed over the last decade in several medical centres in an attempt to provide some meaningful quality of life for individuals with this devastating condition. And home care has been shown to be both feasible and cost effective (though costs remain relatively high) so that patients are no longer institutionalised. Nevertheless, this group of patients do badly on any scale that employs objective factors to measure quality of life: they score very low on general mobility, selfcare and disruption of social and personal relationships for instance. On the other hand, research shows that, on scales measuring subjective factors like feelings of depression and hopelessness. tetraplegics do much better, though still not so well as do many other groups of patients. Yet, while surely living at the edge of what is tolerable for human beings, they express a strong desire to continue living: the great majority, given the choice, would choose to be ventilated again. ${ }^{2}$ That fact suggests that the subjective experience of a life is more important than its outward expression and that life itself is valued for many reasons other than the absence of distress. This apparent lack of correlation between the quality of a life and the value put on it by the patient suggests either that tetraplegics are a wholly irrational group of people or that the index of quality of life, as it stands, seriously undervalues survival. The latter seems more likely.

This might not be important if QALYs were used in a way that guaranteed that they reflected people's actual preferences and attitudes by being restricted to the context of the doctor-patient relationship. But, in order to fulfil the purpose for which they were specifically designed. most QALY ratings use a fairly simple matrix measuring disability and distress, the results of which are then applied not to the course of the illness of actual patients but to a standard typical course, itself based on a general judgement of the average quality reduction associated with a particular treatment under assessment. It is here that failure to understand the subjective experience of such a life becomes morally significant. Research on tetraplegic patients suggests that judge- 
ments about the value of survival versus quality of life cannot reliably be made by doctors on behalf of patients nor extrapolated from one patient to another. Still less can such judgements or measures serve as the basis for generalisations by health economists as to resource priorities, at least if we are looking for something more rigorous than a very rough and ready guide to decision making. The denial of the right to treatment of some patients is serious enough, surely, to require more than that.

QALYs clearly presuppose a utilitarian framework of thought and their validity depends on its strengths. This becomes clear in the context of resource allocation, for instance, where some of the largest claims for the QALY method are made. We are invited to agree that rational self interest demands a certain distribution of healthcare, viz that distribution which will secure maximum benefit, and that QALYs help us to secure this. Whatever we make of the latter claim, the force of the claim to rational self interest is said to be decisive. For the rationality of a decision or procedure is supposed to guarantee that, given the same information to work with, all rational persons will arrive at the same conclusion. Certainly it seems intuitively right to say that it would be both irrational and a failure in justice to patients to distribute health resources in such a way that one achieved less good than was possible. We want to bring about the most good we can. That much we can all agree on. But now everything hangs on how we interpret 'the most good'. And there seem to be at least two possible interpretations to be considered.

Utilitarian economics equate the most good with the greatest aggregate benefit. To see how this model of rational choice works we can play a game: I offer you a choice between two options, $\mathrm{A}$ and $\mathrm{B}$. If you pick A I give you $10 \mathrm{p}$. If you pick $\mathrm{B}$, however, I toss a fair coin. If it comes up heads I give you $30 \mathrm{p}$ but if it comes up tails you get nothing. Thus the expected monetary value of $\mathrm{A}$ is $10 \mathrm{p}$ while for $\mathrm{B}$ it is [ $p$ (heads) $\times 30]+[p$ (tails $) \times 0]=[1 / 2 \times 30]+$ $[1 / 2 \times 0]=15 \mathrm{p}$. The expected monetary value of $B$ is greater than that of $A$ and, especially if we play repeatedly, B therefore seems to be the sensible option to take. Applied to the allocation of health resources it appears that rationality requires that we choose the distribution which maximises aggregate benefits. In order to do that we need to know which treatment of which condition generates most QALYs; we can then distribute accordingly.

On such a view persons are taken to be rational maximisers of their own good. One might wonder about the precise connection between rationality and self interest and the assumption here of what is a highly contestable and utilitarian concept of human nature. However, even assuming that concept is largely correct, it does not follow that 'the most good' means 'the greatest aggregate benefit'. Let us play a second game. This time we can play only once. Again I offer you a choice between option $\mathrm{A}$ and option B. However if you pick A this time I give you $£ 10,000,000$. If you pick B I will toss a fair coin. If it comes up heads I give you $£ 30,000,000$ but if it comes up tails you get nothing. The calculation of expected monetary value is much as before: $\mathrm{A}$ is worth $£ 10,000,000$ and B's value is

$$
\begin{aligned}
{[p(\text { heads }) \times} & \times 30,000,000]+[p(\text { tails }) \times 0] \\
& =[1 / 2 \times 30,000,000]+[1 / 2 \times 0] \\
& =£ 15,000,000
\end{aligned}
$$

As before then, the value of $\mathrm{B}$ is greater than that of $\mathrm{A}$. Nevertheless in this case almost everyone prefers A to B. That seems to be because most of us, when a choice is momentous (indicated here by the higher sums involved and by the restriction on how often one can play) would choose to play safe rather than to maximise benefits. And a way to play safe is to make the worst possible outcome as good as possible. It is this reasoning strategy, known as the maximin principle, that explains our favouring of option $\mathrm{A}$ in a situation of critical choice. ${ }^{3}$ Now if we assume that the allocation of health resources is a matter of moment, that is, that the duration and quality of individual lives are fundamentally different in kind from most other goods distributed in society, then this model of rational choice suggests that we ought to aim to make the worst off better off. We ought therefore to 
distribute health resources where need is greatest: to the care of ventilator dependent tetraplegics, for example. And QALY arithmetic will be of little use in this case, as has been pointed out, because it is insensitive to differences in degree of need except insofar as needs correlate with the degree of benefit per unit cost that a treatment confers. It is not at all clear, then, that the achievement of the greatest good requires QALY arithmetic or totting up the greatest aggregate benefit.

At this stage one can sympathise with health authorities and managers who, though grateful for the guidance of economists and moral philosophers, reject what they see as neat formulae as a way of taking their tough decisions and turn instead to the public arena. There is a growing movement in favour of making rationing (which is inevitable) explicit, and involving the public in the making of decisions. A district health authority, it is claimed, has a responsibility to inform the public of the repercussions of the decisions it takes since 'any progression down that route has to be understood and ultimately approved'. ${ }^{4}$ But we need to be cautious here. The clear implication is that only by involving the public in policy making will we get a true picture of the real preferences of people in regard to healthcare allocation and therefore of what serves the general interest best. But while agreeing with the need to involve the public more fully in the debate about resources and their distribution, one cannot but feel some alarm for groups like tetraplegics if their care were to be subject to the whim of the majority, as in the Oregon experiment. ${ }^{5}$ This is no elitist objection: it has never been thought to be one of the many strong points of the democratic decision procedure that, by itself, it guarantees the justice of social arrangements. Indeed, many of the items morally most important to democracy itself are protected from democratic decision and among these, the systematic victimisation of one group (say, the unhealthy) by another is surely one of the most important. One could only conclude that what the majority think is right in regard to the allocation of medical resources is right, if one assumed that it is the exercise of the capacity for choice, rather than the satisfaction of needs, that is of ultimate moral value in this area. Here one can see how a utilitarianism based on the satisfaction of preferences approximates to its standard rival, an ethics of autonomy, and the inherent dangers of each as a basis for social policy.

In 1942 the philosopher Simone Weil wrote that caring necessarily involves 'a recognition that the sufferer exists, not only as a unit in a collection, or a specimen from the social category labelled "unfortunate", but as a man, exactly like we are, who was one day stamped with a special mark of affliction. For this reason it is enough, but it is indispensable, to know how to look at him in a certain way'. ${ }^{6}$ That looking involves both compassion and justice. What it certainly rules out is the assigning of a QALY, or democratically-arrived-at, value to a life.

\section{References}

1 Carr-Hill RA, Morris J (1991) Current practice in obtaining the 'Q' in QALY's: a cautionary note. $B M J$ 303: 699-701.

2 Gardner BP, Theocleous F, Watt JWH, Krishnan KR (1985) Ventilation or dignified death for patients with high tetraplegia. BMJ 291: 1620-1622.

3 Rawls JA (1971) Theory of Justice. OUP.

4 Cochrane M, Ham C, Heginbotham C, Smith R (1991) Rationing: at the cutting edge. BMJ 303: $1039-1042$.

5 Dean M (1991) The Oregon trail reaches Britain. The Lancet 388: 1133-1134.

6 Weil S (1968) On Science Necessity and the Love of God. OUP. 